Research Article

\title{
Effect of Physicochemical Properties of Co and Mo Modified Natural Sourced Hierarchical ZSM-5 Zeolite Catalysts on Vanillin and Phenol Production from Diphenyl Ether
}

\author{
Anita Nur Ramadhani, Iman Abdullah, Yuni Krisyuningsih Krisnandi* \\ Department of Chemistry, Faculty of Mathematics and Natural Science, Universitas Indonesia, Depok-16424, \\ Indonesia \\ Solid Inorganic Framework Laboratory, Department of Chemistry, Faculty of Mathematics and Natural Science, \\ Universitas Indonesia, Depok-16424, Indonesia
}

Received: $7^{\text {th }}$ January 2022; Revised: 19th February 2022; Accepted: $20^{\text {th }}$ February 2022

Available online: 21th February 2022; Published regularly: March 2022

Abstract

The conversion of lignocellulose biomass to value-added chemicals is challenging. In this paper, the conversion process of diphenyl ether (DPE) as a model lignin compound to phenol and vanillin compounds involved a bifunctional catalyst in reaching the simultaneous one-pot reaction in mild conditions with a high yield product. The catalysts used in this conversion are hierarchical ZSM-5 zeolites and their cobalt oxide and molybdenum oxide impregnated derivate. The ZSM-5 zeolites were synthesized using alternative precursors from natural resources, i.e., Indonesian natural zeolite and kaolin. The physicochemical properties of the catalysts were determined with various characterization methods, such as: X-ray Diffraction (XRD), Fourier Transform Infra Red (FT-IR), Scanning Electron Microscope - Energy Dispersive X-ray (SEM-EDX), X-ray Fluorescence (XRF), Surface Area Analyzer (SAA), and $\mathrm{NH}_{3}$-Temperature Programmed Desorption ( $\mathrm{NH}_{3}$-TPD). The catalytic activity on conversion of DPE substrates showed that the $\mathrm{MoO}_{\mathrm{x}} / \mathrm{HZSM}-5$ produced the highest \%yield for phenol and vanillin products; $31.96 \%$ at $250{ }^{\circ} \mathrm{C}$ and $7.63 \%$ at $200{ }^{\circ} \mathrm{C}$, respectively. The correlation study between the physicochemical properties and the catalytic activity shows that the dominance of weak acid $(>40 \%)$ and mesoporosity contribution (pore size of $\sim 9$ $\mathrm{nm}$ ) play roles in giving the best catalytic activity at low temperatures.

Copyright (C) 2022 by Authors, Published by BCREC Group. This is an open access article under the CC BY-SA License (https://creativecommons.org/licenses/by-sa/4.0).

Keywords: Diphenyl ether; Co oxide/ZSM-5; Mo oxide/ZSM-5; Vanillin and Phenol production; catalytic conversion; natural sourced ZSM-5

How to Cite: A.N. Ramadhani, I. Abdullah, Y.K. Krisnandi. (2022). Effect of Physicochemical Properties of Co and Mo Modified Natural Sourced Hierarchical ZSM-5 Zeolite Catalysts on Vanillin and Phenol Production from Diphenyl Ether. Bulletin of Chemical Reaction Engineering \& Catalysis, 17(1), 225-239 (doi: 10.9767/bcrec.17.1.13372.225-239)

Permalink/DOI: https://doi.org/10.9767/bcrec.17.1.13372.225-239

\section{Introduction}

The main challenge in fine chemical industrial development is the replacement of fossil resources with sustainable resources. The utiliza-

* Corresponding Author.

Email: yuni.krisnandi@sci.ui.ac.id (Y.K. Krisnandi) tion of lignocellulosic biomass has recently shown a rapid development due to being the only renewable resource of organic carbon in nature, which provides advantages in value-added chemical production [1]. The chemical structure of lignin has many aromatic structures with specific ether bonding for each monolignol [2] 
that become a source of high-value compounds, such as vanillin and phenol [3]. However, regarding the complexity of the lignin structure, the conversion mechanism becomes unclear. The simplification of the complexity of the lignin fraction can be seen in several existing model compounds, such as diphenyl ether (DPE) as a representative of 4-O-5 bonding, phenethyl phenyl ether (PPE) as representative of $\beta$-O-4 bonding and benzyl phenyl ether (BPE) as representative of a-O-4 bonding [4].

ZSM-5 as a heterogeneous catalyst is commonly used in biomass conversion because of its porosity, leading to a good shape selectivity of products and good thermal stability [5]. Deepa et al. reported that the presence of conventional HZSM-5 shows that biomass depolymerization produced around $60 \%$ of aromatic monomers [6]. Hereafter, several modifications in ZSM-5, such as modification of the pores into hierarchical pores and the addition of metal oxides, have shown to increase the catalytic effectiveness in biomass conversion, especially to improve the selectivity of the reaction product.

$\mathrm{CoO}_{\mathrm{x}} / \mathrm{HZSM}-5$ in the pyrolysis reaction produced the highest distribution yield for monocyclic aromatic compounds [7] and facilitated the conversion of bio-oil into phenolic and guaiacol products with the increasing selectivity of $9.2 \%$ and $15.3 \%$ compared with the noncatalyzed reaction [8]. Also reported, the pyrolysis reaction's selectivity to produce phenolic derivative products facilitated by Mo modified ZSM-5 was $30 \%$ [9]. The impregnation of the Mo oxide on ZSM-5 produced monocyclic aromatic with the highest yield, and selectivity was $84.5 \%$ in fast pyrolysis reaction [10]. Hydrogenolysis of aryl ether bond over heterogenous cobalt-based catalysts also show the $97 \%$ selectivity of $\mathrm{C}-\mathrm{O}$ bond ruptured products was achieved from DPE model lignin compound, with the major product were phenol and benzene [11]. Also reported that Mo-based catalysts leading the effective hydrodeoxygenation of biomass-derived oxygenates, such as lignin model compounds [12,13]. Based on these several reports, it is shown that combination of acid sites in zeolite and metal oxide species, such as cobalt oxides and molybdenum oxides can effectively improve the lignin conversion.

For research purposes, the synthesis of ZSM-5 catalysts usually uses pro analyst precursors. Nonetheless, taking into account the environmental, economic, and abundances in nature, the use of natural resources as alternative precursors can be a distinct added value. It has been studied the success of zeolite synthesis from alternative resources, for example, ka- olin [14,15], rectorite with diatomite [16], and a combination of Indonesia zeolite and kaolin [17]. In this work, the ZSM-5 catalyst was synthesized using the alternative precursor, i.e. Indonesian natural zeolite and kaolin. The assynthesized ZSM-5 then was converted to HZSM-5, followed by modification with molybdenum and cobalt oxides to provide more active sites in the catalyst.

In this present work, we aimed to study the conversion of diphenyl ether (DPE), one of the lignin models, to more useful chemicals, such as phenolic compounds and vanillin using Mooxides and Co-oxides-modified HZSM-5 catalysts $\left(\mathrm{MoO}_{\mathrm{x}} / \mathrm{HZSM}-5\right.$ and $\left.\mathrm{CoO}_{\mathrm{x}} / \mathrm{HZSM}-5\right)$. The correlation between physicochemical properties and activity of catalyst on DPE conversion, as well as the optimum conditions to obtain the highest \%yield of vanillin and phenol are discussed.

\section{Materials and Methods}

\subsection{Materials}

Indonesian natural zeolite was from Bayat Klaten, Central Java. The kaolin used was provided by PT Aneka Kaolin Utama, Belitung Indonesia. $\mathrm{NaOH}$ pellet $99 \%$, nitric acid, hydrochloric acid, hydrogen peroxide $30 \%$, glacial acetic acid, sodium acetate tetrahydrate, sodium bicarbonate, ethanol, trisodium citrate dihydrate, $\mathrm{Co}\left(\mathrm{NO}_{3}\right)_{2} .6 \mathrm{H}_{2} \mathrm{O}, \mathrm{NH}_{4} \mathrm{NO}_{3}$, and methanol were purchased by Merck (Germany). Tetra-propylammonium hydroxide (TPAOH $40 \%$ ), $\left(\mathrm{NH}_{4}\right)_{6} \mathrm{Mo}_{7} \mathrm{O}_{24} .4 \mathrm{H}_{2} \mathrm{O}$, and poly diallyldimethylammonium chloride acrylamide (PDDAM, $10 \%$ ) purchased from Sigma Aldrich, US. And the phosphoric acid (97\%) was purchased from PT. Smart Lab Indonesia.

\subsection{Synthesis of Hierarchical ZSM-5 Catalyst from Natural Resources}

Natural zeolite and kaolin were pre-treated with the activation, purification, fragmentation, and calcination processes following the procedure from Rohayati et al. [18]. The synthesis of hierarchical ZSM-5 using a molar ratio of $3 \quad \mathrm{Al}_{2} \mathrm{O}_{3}: 64.35 \quad \mathrm{SiO}_{2}: 10.07 \quad(\mathrm{TPA})_{2} \mathrm{O}$ : $3571.66 \mathrm{H}_{2} \mathrm{O}$. Fragmented Indonesia zeolite and extracted silica from kaolin as the precursors were mixed with $\mathrm{H}_{2} \mathrm{O}$, stirred overnight. Furthermore, TPAOH and TEOS were added dropwise into the mixture while stirring at 100 ${ }^{\circ} \mathrm{C}$. Then, the $\mathrm{pH}$ solution was adjusted to \pm 11 using acetic acid glacial followed by aging for three hours. Afterward, a certain amount of PDD-AM was slowly added into the reaction 
mixture at room temperature and stirred for 24 h. After stirring, the mixture was transferred into an autoclave for further crystallization at $170{ }^{\circ} \mathrm{C}$ for $144 \mathrm{~h}$. The crystals were washed with $\mathrm{H}_{2} \mathrm{O}$ and then dried in the oven at $60{ }^{\circ} \mathrm{C}$, then calcined in the atmospheric pressure at $550{ }^{\circ} \mathrm{C}$ for five hours [19]. The as-synthesized hierarchical ZSM-5 then was named ZSM-5.

\subsection{Preparation of Hierarchical HZMS-5 Cata- lyst}

Multiple ammonium exchange was carried out using a solution of $\mathrm{NH}_{4}{ }^{+} 1 \mathrm{M}$ at $90{ }^{\circ} \mathrm{C}$ for two hours under stirring for three repetitions. The resulting $\mathrm{NH}_{4} / \mathrm{ZSM}-5$ then was calcined gradually at $550{ }^{\circ} \mathrm{C}$ for 5 hours to produce H/ZSM-5 [20] and named as HZSM-5.

\subsection{Preparation of Hierarchical $\mathrm{CoO}_{\times} / \mathrm{ZSM}-5$ and $\mathrm{MoO}_{\mathrm{x}} / \mathrm{ZSM}-5$ Catalysts}

Catalyst modification was carried out by wet impregnation for $10 \%$ wt metal loaded by adding $1.1313 \mathrm{M}$ of $\mathrm{Co}\left(\mathrm{NO}_{3}\right)_{2} \cdot 6 \mathrm{H}_{2} \mathrm{O}$ or $0.0355 \mathrm{M}$ of $\left(\mathrm{NH}_{4}\right)_{6} \mathrm{Mo}_{7} \mathrm{O}_{24} .4 \mathrm{H}_{2} \mathrm{O}$ into 1 gram of ZSM-5 or HZSM-5 using spraying method multiple times to form a paste [21] and left for 24 hours before it was calcined gradually at $550{ }^{\circ} \mathrm{C}$ to obtained $\mathrm{CoO}_{\mathrm{x}} / \mathrm{ZSM}-5$ [22] and at $500{ }^{\circ} \mathrm{C}$ to obtained $\mathrm{MoO}_{\mathrm{x}} / \mathrm{ZSM}-5$ [23]. Furthermore, the asprepared catalysts were named $\mathrm{CoO}_{\mathrm{x}} / \mathrm{ZSM}-5$, $\mathrm{CoO}_{\mathrm{x}} / \mathrm{HZSM}-5, \mathrm{MoO}_{\mathrm{x}} / \mathrm{ZSM}-5$, and $\mathrm{MoO}_{\mathrm{x}} / \mathrm{HZSM}-$ 5.

\subsection{Characterization of Catalysts}

All catalysts were then characterized using XRD, FT-IR, XRF, SEM, EDS, SAA, and $\mathrm{NH}_{3}$. TPD. The FT-IR analysis used Alpha - Bruker, while the XRD was carried out in PANalytical XPert PRO 2318 diffractometer with $\mathrm{Cu}-\mathrm{K}$ radiation $(K=1.54184 \AA)$ as the incident beam. Analysis XRF using PANanalytical epsilon1. The SEM-EDS measurement using FE-SEM JIB-4610F, Schottky electron gun robe current (200nA), electron backscatter diffraction (EBSD), cathodoluminescence (CLD). Moreover, for the surface area analyzer, use Quantachrom-Evo Surface Area and Pore Analyzer. And for the acidity properties was analyzed using $\mathrm{NH}_{3}$-TPD Chemisorb 2750 micrometric, with the sample heated at $350{ }^{\circ} \mathrm{C}$ for 60 min under He gas (inert) as the pre-treatment, followed by the $\mathrm{NH}_{3}$ adsorption was carried out at $100{ }^{\circ} \mathrm{C}$ for 30 minutes using $\mathrm{NH}_{3} 5 \%$ in $\mathrm{He}$ $(\mathrm{v} / \mathrm{v})$, then purged with $\mathrm{He}$ gas (inert) at the same temperature, for 30 minutes. Afterward, the $\mathrm{NH}_{3}$ desorption was carried out at a tem- perature of $100-700{ }^{\circ} \mathrm{C}$ with an increasing speed of $10{ }^{\circ} \mathrm{C} /$ minute, then held for 15 minutes at the temperature of $700{ }^{\circ} \mathrm{C}$, with the entire gas flow rate of $40 \mathrm{~mL} / \mathrm{min}$.

\subsection{Catalytic Activity Test}

The conversion reaction was performed in a batch reactor shown in Figure 1. The procedure was following Deepa et al. [6] and Pratama et al. [17] with modification. The reaction was carried out under an inert condition with $2 \mathrm{~atm}$ of $\mathrm{N}_{2}$ at room temperature. The solvent was water: ethanol $(1: 1 \mathrm{v} / \mathrm{v})$ mixture in a total volume of $25 \mathrm{~mL}$. The amount of DPE and the catalyst added was $0.25 \mathrm{~g}$ and $0.125 \mathrm{~g}$, respectively. The reaction was performed under a stirring condition with $500 \mathrm{rpm}$ for $30 \mathrm{~min}$ [17]. The reaction temperature varied at 150,200 , and 250 ${ }^{\circ} \mathrm{C}$.

After the reaction, the filtrate was separated and prepared for analysis with the HPLC using PG LC210 equipped with C18 column, and a mixture of methanol: distilled water (80:20) as eluent. The \% conversion of DPE, and the \% yield of phenol and vanillin are calculated using the standard calibration curve and determined using following equations:

$\%$ DPE Conversion =

$\frac{\text { Init. Substrate Mass( } g \text { )-Residual Mass ( } g \text { ) }}{\text { Substrate Mass (g) }} \times 100 \%$

$$
\text { Substrate Mass ( } g \text { ) }
$$

$\%$ Yield $=$

$\frac{\text { Product Concent. (mg / L) } x \text { Solution Volume (L) }}{\text { Substrate Mass (g) }} \times 100 \%$

\section{Results and Discussion}

\subsection{Catalyst Characterizations}

Figure 2 shows the diffractogram of all asprepared catalysts, which reveals the specific

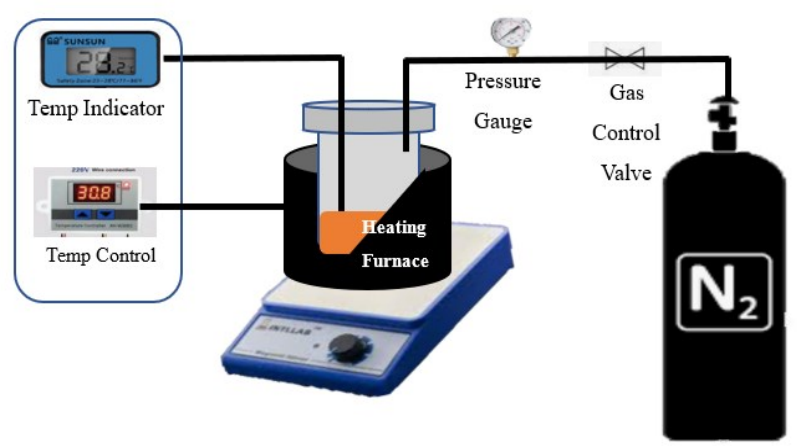

Figure 1. Schematic diagram of DPE conversion in a batch reactor 
pattern for ZSM-5 based on JCPDS 49-0657 [24] that in angel $2 \theta=7-10^{\circ}, 22-25^{0}[25,26]$. It depicts that the MFI (Mordenite Framework Inverted) as the pentasil framework was successfully synthesized. Moreover, as-synthesized ZSM-5 also has another phase as the presence of a strong peak around the angle of 26.7 which is probably the quartz phase. This due to the precursor from the natural resources, so the quartz phase of unreacted silica can be found in the material.

Furthermore, Figure 2 shows new diffraction as $\mathrm{Co}_{3} \mathrm{O}_{4}$ phase $\left(2 \theta=19^{\circ}, 31^{\circ}, 37^{\circ}, 45^{\circ}, 56^{\circ}\right.$, $59^{\circ}$ ) in cobalt oxide modified catalysts referred to JCPDS No. 42-1467 [27]. The XRD patterns of Mo oxide modified catalysts also show new diffraction peaks for $\mathrm{MoO}_{3}$ phase $\left(2 \theta=13^{\circ}, 23^{\circ}\right.$, $27^{\circ}, 34^{\circ}, 38^{\circ}, 46^{\circ}, 49^{\circ}, 50^{\circ}, 51^{\circ}, 53^{\circ}, 54^{\circ}, 56^{\circ}, 59^{\circ}$, $64^{\circ}$ ) as referred to JCPDS No. 05-0508 [28]. These results inform that the incorporation of Co-oxide or Mo-Oxide into ZSM-5 was done successfully.

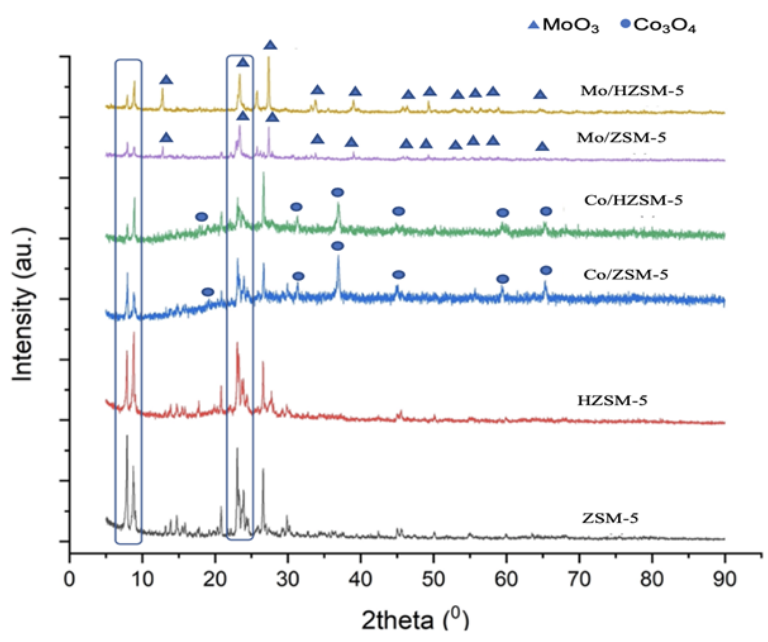

Figure 2. XRD patterns of as-prepared and modified ZSM-5 catalysts
FT-IR spectra for the as-prepared catalysts can be seen in Figure 3. In the wavenumber around $3500 \mathrm{~cm}^{-1}$ a broad band appeared in all spectra, which is assigned to water molecules that are hydrogen-bonded to silanol groups (Si$\mathrm{OH})$ from the surface of ZSM-5 [22,29]. There were differences in its intensity in the spectra of Mo and Co impregnated ZSM-5 and HZSM5 , indicating the closure of the area due to the metal impregnation process in ZSM-5 zeolite. Furthermore, the other typical peaks of the MFI structure of ZSM-5 zeolite are shown as the absorption band of asymmetric stretching from the $\mathrm{T}-\mathrm{O}$ at $1075-1250 \mathrm{~cm}^{-1}$, symmetric stretching of T-O at $820-650 \mathrm{~cm}^{-1}$, and at 650 $500 \mathrm{~cm}^{-1}$ assigned as pentasil double five rings [29].

Additional peaks appear in the fingerprint area between $1000-500 \mathrm{~cm}^{-1}$ for all the asprepared catalysts, indicating the presence of metal oxide in ZSM-5. The characteristic bands of $\mathrm{MoO}_{3}$ show absorbance bands around 999995, 900-877, 561-554 $\mathrm{cm}^{-1}$ [30]. Furthermore, the additional characteristic peaks for $\mathrm{Co}_{3} \mathrm{O}_{4}$ show around 667, 626, and $580 \mathrm{~cm}^{-1}$ [31,32]. This FT-IR analysis provides additional data implementation for as-prepared catalysts and supports the characterization of the XRD diffractogram, which shows the successful process of preparation catalysts.

Scanning Electron Microscopy (SEM) characterization provides information on the catalyst morphology. Figure 4 informs the morphology of all as-prepared catalysts showing the coffin-like or hexagonal crystal geometry [33]. Specific to the Figure 3 (c)-(f), the Co or Mo oxides anchoring to the catalyst's surface contributes to changing the surface of the ZSM-5 catalysts to become slightly rougher.

The elemental composition of the catalyst is analyzed by XRF and EDS methods. The XRF data reveals the element composition in a

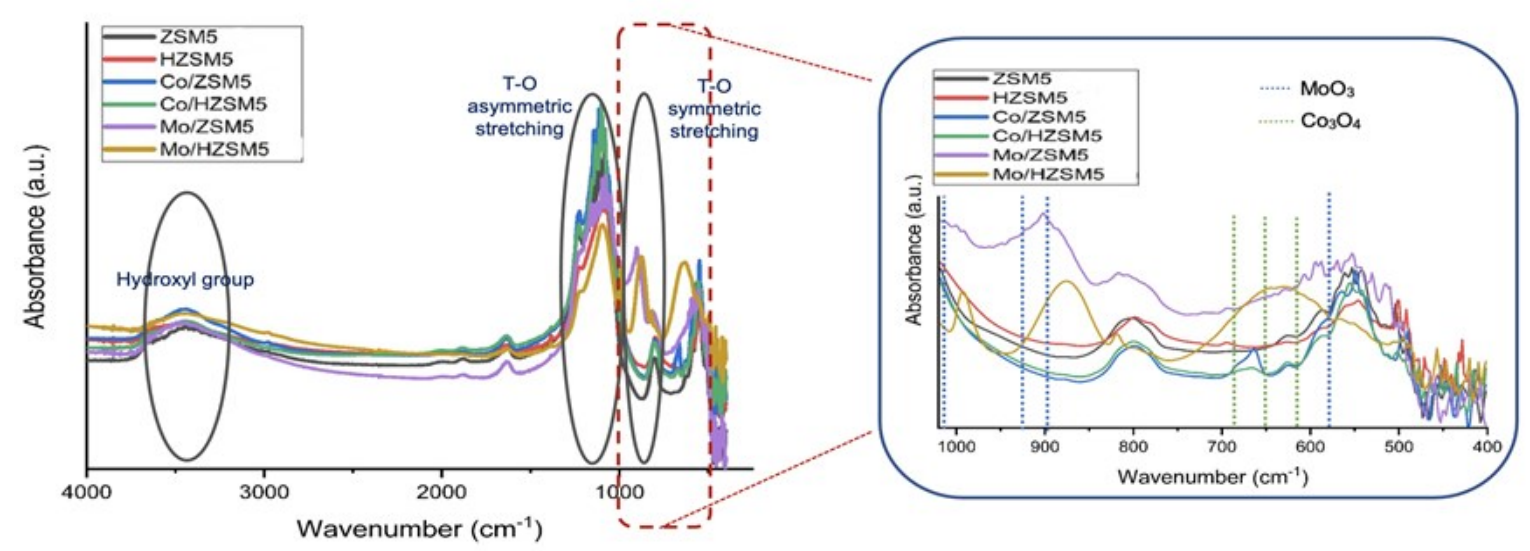

Figure 3. FT-IR spectra of as-prepared catalysts 
bulky state, while the EDS data show the composition of the elements on the surface. The summary of the Si/Al ratio and the loaded metal of the catalysts are shown in Table 1. Generally, based on XRF data, there was no significant change in the $\mathrm{Si} / \mathrm{Al}$ ratio of the catalyst after the preparation of HZSM- 5 and the metal oxide impregnation process. In addition, the EDS data showed that the \%wt of Na content was significantly decreased in HZSM-5, indicating an effective cation exchange process. Furthermore, the \%wt loading of the Co-oxide and Mo-oxide is close to the expected amount of metal oxide. As for metal oxides that are not incorporated into the catalyst, it could be caused by the aggregation of metal oxide groups on the outside of the catalyst.
Furthermore, the porosity and textural properties of the catalyst were analyzed using the BET and BJH methods. The adsorptiondesorption isotherm graphs (Figure 5) show that as-prepared catalysts have a type IV isotherm curve, which indicates monolayer adsorption at low pressure and multilayer adsorption in high pressure, and with the existence of hysteresis loop that indicates the hierarchical porosity [33-35]. The adsorption and desorption isotherm curves show small hysteresis, that could be due to the existence of impurities from the natural precursors which influenced the formation of pores in ZSM-5. Furthermore, from discussion in XRD data, it can also be seen that there is a quartz phase that might cause pore-blocking within the ZSM-5 framework.

Tabel 1. Summary Si/Al and metal loading (\%wt) in catalysts by XRF and EDS method

\begin{tabular}{|c|c|c|c|c|c|c|c|}
\hline \multirow{2}{*}{ Catalyst } & \multicolumn{3}{|c|}{ XRF } & \multicolumn{4}{|c|}{ EDS } \\
\hline & Mo & $\mathrm{Co}$ & Si/Al Ratio & $\mathrm{Na}$ & Mo & Co & Si/Al Ratio \\
\hline ZSM-5 & - & - & 12.11 & 1.20 & - & - & 14.12 \\
\hline HZSM-5 & - & - & 13.20 & 0.50 & - & - & 14.65 \\
\hline $\mathrm{CoO}_{\mathrm{x}} / \mathrm{ZSM}-5$ & - & 8.30 & 11.44 & - & - & 7.00 & 12.04 \\
\hline $\mathrm{MoO}_{\mathrm{x}} / \mathrm{ZSM}-5$ & 7.94 & - & 11.30 & - & 9.60 & - & 11.32 \\
\hline $\mathrm{CoO}_{x} / \mathrm{HZSM}-5$ & - & 7.36 & 12.12 & - & - & 7.80 & 10.11 \\
\hline $\mathrm{MoO}_{\mathrm{x}} / \mathrm{HZSM}-5$ & 8.19 & - & 11.19 & - & 10.30 & - & 12.00 \\
\hline
\end{tabular}

\section{(a)}
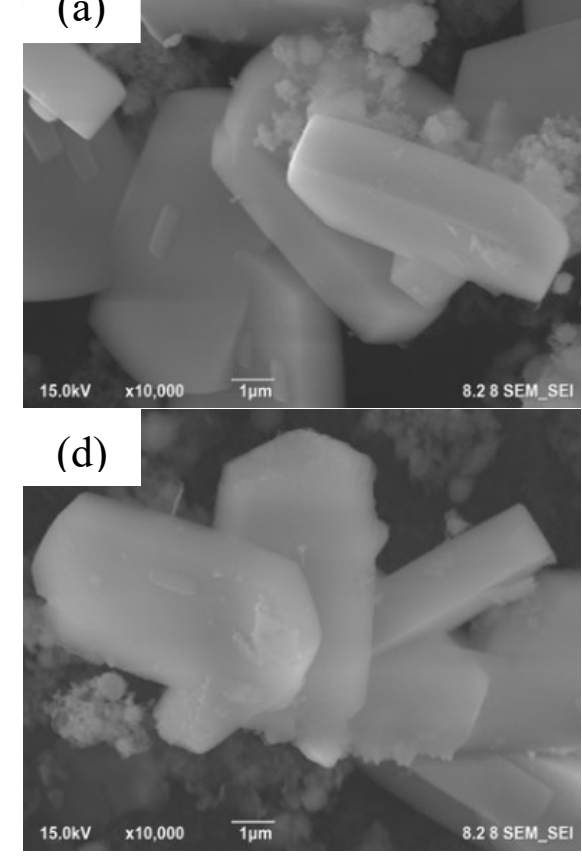

(b)

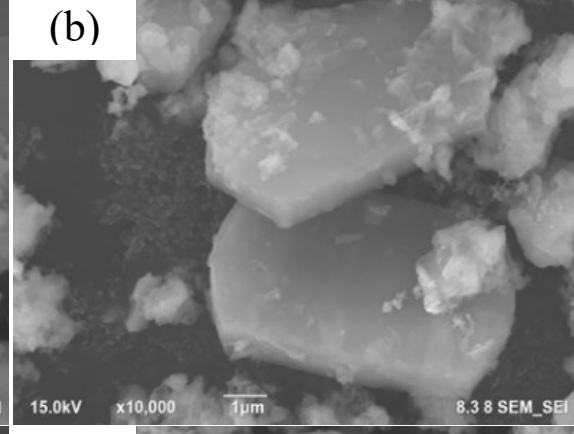

(e)

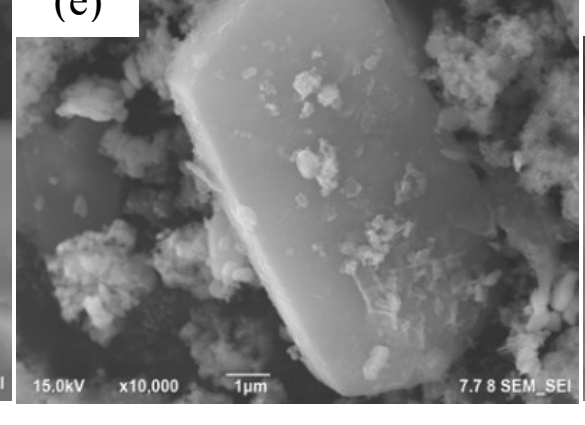

(c)

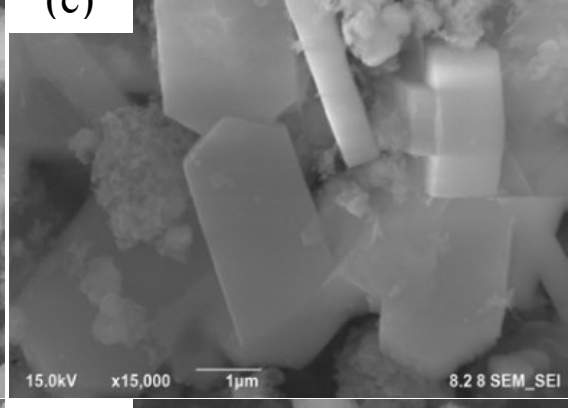

(f)

Figure 4. SEM images for (a) ZSM-5, (b) MoO $/$ /ZSM-5, (c) CoO ${ }_{x} / Z S M-5$, (d) HZSM-5, (e) MoO $/$ HZSM-5, (f) $\mathrm{CoO}_{\mathrm{x}} / \mathrm{HZSM}-5$ catalyst 
The process of cation exchange showed not to significantly change the structural porosity of the catalyst and the textural properties tended to be preserved. Meanwhile, the incorporation of metal oxides in catalysts shows that all the catalysts experienced a reduction in BET surface area except the $\mathrm{CoO}_{\mathrm{x}} / \mathrm{HZSM}-5$. This decrease was mainly due to solid metal species at the pores and/or the external surface of zeolites [21]. Meanwhile, the $\mathrm{MoO}_{\mathrm{x}} / \mathrm{ZSM}-5$ experiences a significant decrease in BET surface area and pore volume. This condition is because of the agglomeration of Mo oxide in the pore.

In contrast, the increase of surface area in $\mathrm{CoO}_{\mathrm{x}} / \mathrm{HZSM}-5$ due to the aggregation of Cooxides on the external zeolite surface, which leads to the creation of more volume and pore. This phenomenon was also observed by Krisnandi et al. when preparing iron oxide modified NaY Zeolite [36]. Moreover, the $t$-Plot analysis showed the metal oxides reside in both micropores and mesopores catalysts. The textural properties of the catalysts are summarized in Table 2.

Data from Table 2 show that Mo impregnated HZSM-5 led to the pore opening in the mesopore site of catalysts which made a larger size in the distribution pores. Seen also in XRF data of $\mathrm{MoO}_{\mathrm{x}} / \mathrm{HZSM}-5$, that experienced a decrease of Si/Al ratio from 13.20 to 11.19 compared to the HZSM-5 was assumed due to desilication. It was also reported by Kosinov et al. that most of the initially aggregated Mo-oxide at the external surface are dispersed into the pore upon calcination, resulting in the reaction of mobile $\mathrm{MoO}_{3}$ species with framework $\mathrm{Al}$, aluminum molybdate formation, and produced the amorphous $\mathrm{SiO}_{2}$ [37].

The acidity of ZSM-5 and modified ZSM-5 catalysts was determined by $\mathrm{NH}_{3}$-TPD as de-

Tabel 2. Summary of textural properties catalysts based on $\mathrm{N}_{2}$-sorption analysis

\begin{tabular}{|c|c|c|c|c|c|c|c|c|}
\hline \multirow[t]{2}{*}{ Catalyst } & \multicolumn{3}{|c|}{ Surface Area $\left(\mathrm{m}^{2} / \mathrm{g}\right)$} & \multicolumn{3}{|c|}{ Volume@STP (cc/g) } & \multicolumn{2}{|c|}{$\begin{array}{l}\text { gPore Distribution } \\
(\mathrm{nm})\end{array}$} \\
\hline & aBET & bMicro & cMeso & dTotal & eMicro & fMeso & Micro & Meso \\
\hline ZSM-5 & 159 & 75 & 84 & 0.11 & 0.04 & 0.07 & 1.93 & 3.12 \\
\hline HZSM-5 & 149 & 70 & 79 & 0.10 & 0.04 & 0.07 & 1.94 & 2.73 \\
\hline $\mathrm{CoO}_{\mathrm{x}} / \mathrm{ZSM}-5$ & 152 & 72 & 80 & 0.11 & 0.04 & 0.07 & 1.93 & 2.16 \\
\hline $\mathrm{MoO}_{x} / \mathrm{ZSM}-5$ & 58 & 25 & 34 & 0.04 & 0.01 & 0.03 & 1.94 & 2.16 \\
\hline $\mathrm{CoO}_{\mathrm{x}} / \mathrm{HZSM}-5$ & 193 & 84 & 110 & 0.13 & 0.04 & 0.08 & 1.93 & 2.16 \\
\hline $\mathrm{MoO}_{\mathrm{x}} / \mathrm{HZSM}-5$ & 139 & 54 & 85 & 0.14 & 0.03 & 0.11 & 1.94 & 9.28 \\
\hline
\end{tabular}

aBET surface area; bMicropore surface area evaluated by $t$-plot method; aBET surface area, bMicropore surface area evaluated by $t$-plot method; cMesopore surface area calculated using $S_{\mathrm{BET}-} S_{\text {micro, }}$, ${ }^{\mathrm{T}}$ Total pore volume at P/P0 $\sim 0.99$; cMesopore surface area calculated using $S_{\mathrm{BET}-} S_{\text {micro, }}$ dTotal pore volume at P/P0 $\sim 0.99$; eMicropore volume calculated by $t$-plot method; fMesopore volume calculated using $V_{\text {Total }}-V_{\text {micro }}$; eMicropore volume calculated by $t$-plot method; fMesopore volume calculated using $V_{\text {Total }}{ }^{-}$ $V_{\text {micro }}$; PPore distribution based on BJH analysis.
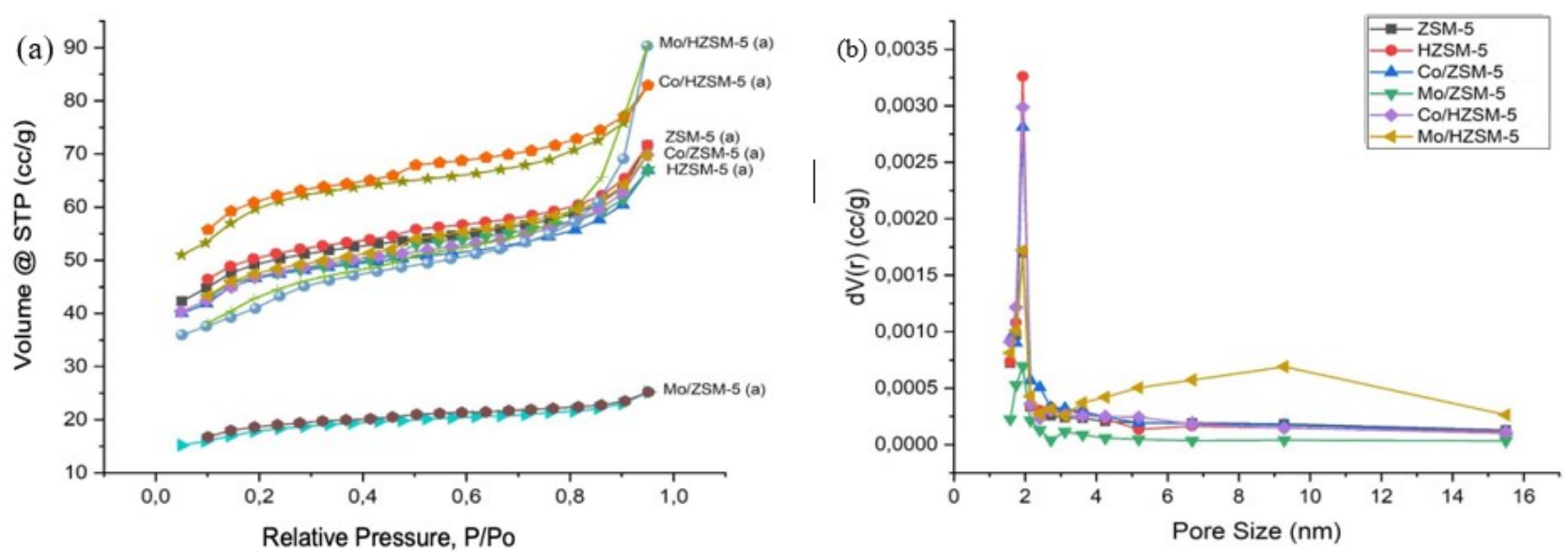

Figure 5. (a) Isotherm of adsorption-desorption curves and (b) pore size distribution of as-prepared catalysts 
picted in Figure 6. The temperatureprogrammed desorption of a basic molecule, such as ammonia ( $\left.\mathrm{NH}_{3}-\mathrm{TPD}\right)$, is one of the most commonly used methods for measuring the surface acidity of porous materials such as zeolites [21,38-39]. With the $\mathrm{NH}_{3}$-TPD analysis, the acid site distribution in catalysts could be estimated. Generally, the acidity distribution can be divided into three regions by Gaussian function as a weak acid, moderate acid, and strong acid site [21,46]. Specific to the ZSM-5 and HZSM-5 acidity profile, the peaks of acid distribution usually appear in two temperature regions [47] or three temperature regions [21,46].

In Figure 6, each curve was divided into three peaks as Gaussian function; the peaks centered ca. $100-250{ }^{\circ} \mathrm{C}, 250-600{ }^{\circ} \mathrm{C}$, and 600 $800{ }^{\circ} \mathrm{C}$ pointing to the desorption of $\mathrm{NH}_{3}$ in weak acid, medium acid, and strong acid positions [21]. The low $\mathrm{Si} / \mathrm{Al}$ ratio $(\mathrm{Si} / \mathrm{Al}$ ratio $=12)$ in as-prepared catalysts caused the $\mathrm{NH}_{3}$ desorption in medium and strong acid sites was found in high temperature regions. It was also reported by Lonyi et al. that the $\mathrm{NH}_{3}-\mathrm{TPD}$ curve of HZSM-5 with $\mathrm{Si} / \mathrm{Al}$ ratio $=15$ have a high temperature region around $550-700{ }^{\circ} \mathrm{C}$ [39]. Table 3 shows the summary of detailed catalysts acidity information of as-prepared catalysts.

Furthermore, Mo incorporated ZSM-5 and HZSM-5 has interestingly changed the acid site property from the strong acid to weak acid, with the \% weak acid content being $48 \%$ and $42 \%$, respectively. Meanwhile, the $\mathrm{CoO}_{\mathrm{x}} / \mathrm{ZSM}-5$ has strong acid as the dominant acid sites, while $\mathrm{CoO}_{\mathrm{x}} / \mathrm{HZSM}-5$ is predominated with medium acid sites.

The change in the acidity of the catalyst is associated with the closure of the acid sites on the surface and the reaction between metal species and the acid site on the outer surface or in the channels $[21,38,40]$. In addition, the data shows the impregnation lead reaction between metal species and protonic acid and would have converted the strong acid into a medium or weak acid.

\subsection{Catalytic Activity}

The \% conversion of the DPE substrate was displayed in Figure 7, showing that the \% conversion of DPE was about $89-91 \%$ conversion for the uncatalyzed reaction, and $96-100 \%$ conversion when catalysts were added, with the highest using the $\mathrm{MoO}_{\mathrm{x}} / \mathrm{HZSM}-5$ catalyst at $200{ }^{\circ} \mathrm{C}$ was $100 \%$ conversion.

Figure 8 reveals the \% yield of the desired compounds of this reaction, phenol and vanillin. The Figure 7(a) shows without a catalyst, the \% yields of phenol fall in the range of $10 \%$ $18 \%$, the highest was $17.65 \%$ at $200{ }^{\circ} \mathrm{C}$, while in the presence of catalysts, the \% yield of phenol was increased, with the highest yield of
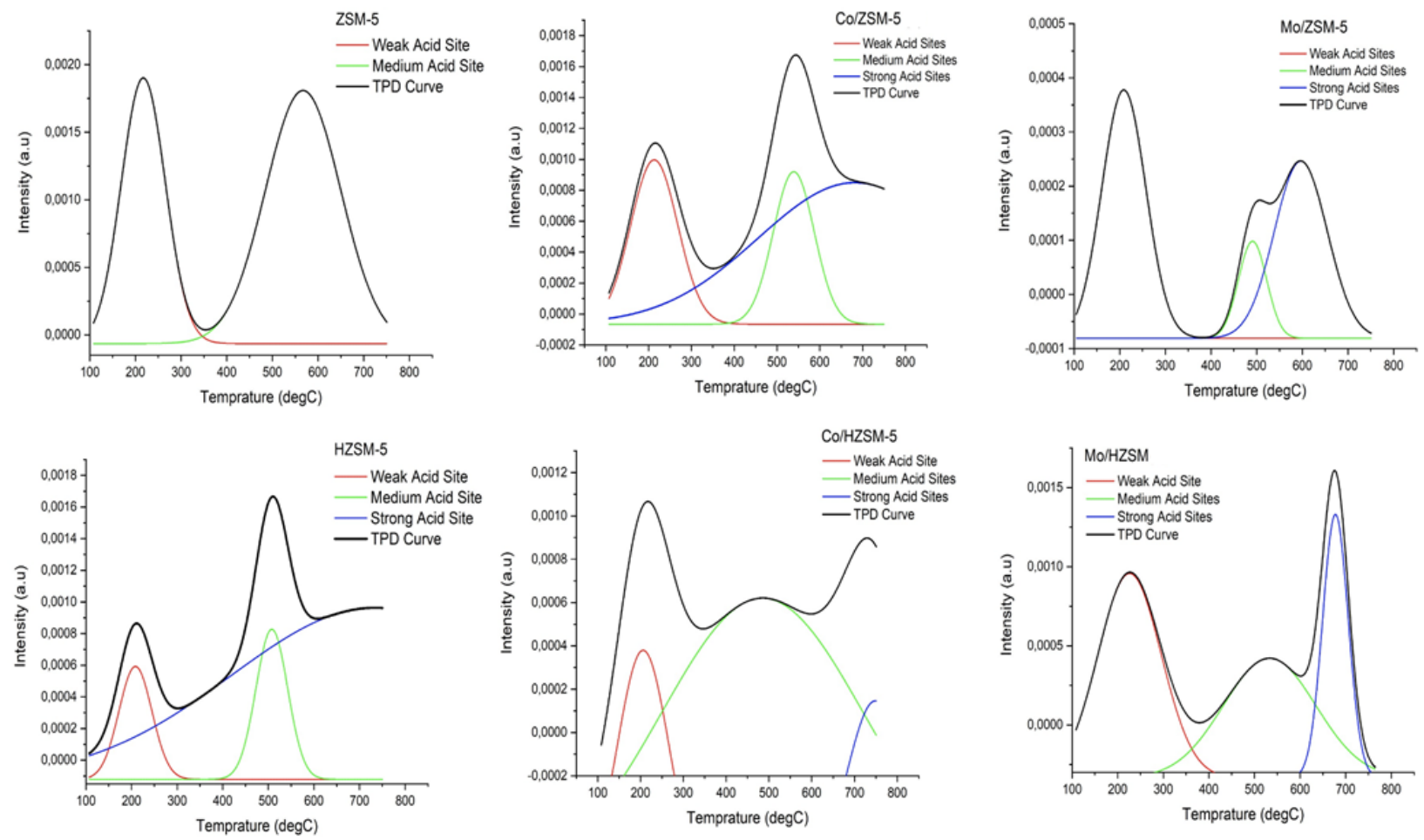

Figure 6. $\mathrm{NH}_{3}$-TPD curves from as-prepared catalysts 
$31.96 \%$ was achieved using $\mathrm{MoO}_{\mathrm{x}} / \mathrm{HZSM}-5$ catalyst at $250{ }^{\circ} \mathrm{C}$. On the other hand, for vanillin, as shown in Figure 8(b), the highest yield was 7.63\% over $\mathrm{MoO}_{\mathrm{x}} / \mathrm{HZSM}-5$ catalyst at a temperature of $200{ }^{\circ} \mathrm{C}$.

3.3. Correlation of Physicochemical Properties of Catalysts and the Catalytic Activity

The reaction of DPE molecules as organic molecules is influenced by temperature, so as expected the \% conversion of DPE at the reaction temperature $\left(150-250{ }^{\circ} \mathrm{C}\right)$ was high, nearly $100 \%$. It has also been reported that the breaking of $\mathrm{C}-\mathrm{O}-\mathrm{C}$ and aryl ether bonds can occur in the temperature range of $150-300{ }^{\circ} \mathrm{C}$ without using a catalyst [41]. Yao et al. reported that over numerous heterogenous catalysts the DPE conversion above $70 \%$ in $120{ }^{\circ} \mathrm{C}$ [42], furthermore, Zhao et al. reported over $\mathrm{Pd} / \mathrm{C}$ and HZSM-5 in aqueous solution, DPE are converted $100 \%$ at $200{ }^{\circ} \mathrm{C}$ [43]. However, it becomes important to use a catalyst in the reaction to increase the selectivity of desired products, such as vanillin and phenol. In addition, this study showed that phenol and vanillin are the major products from DPE substrate over the as-prepared catalysts. The other possible products are benzene, cyclohexane, cyclohexanol and cyclohexanone, as reported in [44,45]. Thus, further product analysis using other standard compounds or with Liquid Chromatography-Mass Spectrometry (LC-MS) is suggested to be carried out if necessary. According to the catalytic activity and the physicochemical properties, the character of the catalyst that has a significant influence on the production of phenol and vanillin is the composition of the catalyst acidity and the textural/porosity properties.

As observed in this study, where ZSM-5 has two desorption peaks and HZSM-5 has three desorption peaks in $\mathrm{NH}_{3}$-TPD curve as depicted in Figure 6. Furthermore, Engtrakul et al.

Table 3. Acidity profile by $\mathrm{NH}_{3}$-TPD measurement of as-prepared catalysts

\begin{tabular}{|c|c|c|c|c|c|c|c|}
\hline \multirow{2}{*}{ Catalyst } & \multirow{2}{*}{$\begin{array}{l}\text { Acid Amount } \\
(\mathrm{mmol} / \mathrm{g})\end{array}$} & \multicolumn{3}{|c|}{ *Acid Site Content (\%) } & \multicolumn{3}{|c|}{ Peak Position $\left({ }^{\circ} \mathrm{C}\right)$} \\
\hline & & Weak & Medium & Strong & Weak & Medium & Strong \\
\hline ZSM-5 & 0.2870 & 38 & 62 & 0 & 207 & 568 & - \\
\hline HZSM-5 & 0.2199 & 6 & 8 & 85 & 221 & 510 & 703 \\
\hline $\mathrm{CoO}_{\mathrm{x}} / \mathrm{ZSM}-5$ & 0.1803 & 19 & 15 & 66 & 220 & 557 & 726 \\
\hline $\mathrm{MoO}_{\mathrm{x}} / \mathrm{ZSM}-5$ & 0.0532 & 48 & 12 & 41 & 207 & 502 & 635 \\
\hline $\mathrm{CoO}_{\mathrm{x}} / \mathrm{HZSM}-5$ & 0.2595 & 15 & 72 & 13 & 214 & 475 & 732 \\
\hline MoOx/HZSM-5 & 0.1512 & 42 & 36 & 22 & 224 & 526 & 676 \\
\hline
\end{tabular}

*Acid Content determined by $\mathrm{NH}_{3}$-TPD profile deconvolution with Gaussian peaks $\left(\mathrm{R}^{2}>0.95\right)$

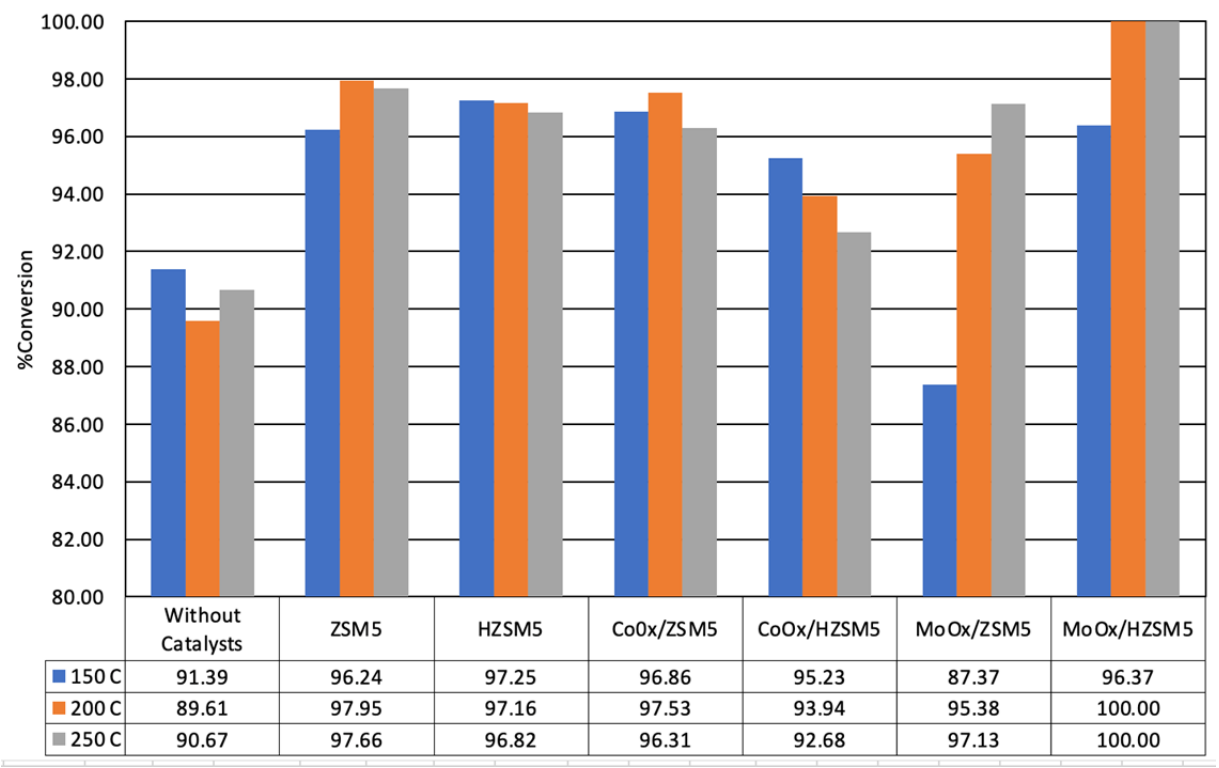

Figure 7. DPE conversion over as-prepared catalysts; reaction condition: $\mathrm{P} \mathrm{N}_{2}=2 \mathrm{~atm} \mathrm{DPE}$ : catalyst ratio $=0.25 \mathrm{~g}: 0.125 \mathrm{~g}$, solvent used (ethanol: $\left.\mathrm{H}_{2} \mathrm{O}\right)=1: 1$ in total volume was $25 \mathrm{~mL}$ 
reported that the temperature peaks are influenced by the $\mathrm{Si} / \mathrm{Al}$ ratio of the catalysts, which the lower $\mathrm{Si} / \mathrm{Al}$ can shift the peaks to higher temperature region $[39,48]$.

In addition, the incorporation of metal oxides in zeolite has been reported can change the catalysts' acidity, such as new peaks appearing at high-temperature regions [47] and changing the dominant composition of the acid sites $[21,28,49,50]$. Specific to incorporated with molybdenum oxide, the low temperature desorption peak experienced an increase $[28,49]$. Meanwhile, the incorporation with cobalt oxide tends to increase desorption peak at higher temperature region [50]. This phenomenon is similar to what was found in this study, that incorporating molybdenum oxide can increase acidity in the low-temperature region. In contrast with the cobalt oxides can increase acidity in relatively high temperature region.

Specific to the expected mild conditions in this study, where the reaction temperature is low, ranging from $150-250{ }^{\circ} \mathrm{C}$, it is seen that the catalyst with the high weak acid content can facilitate the reaction optimally. The modified Mo catalyst with the weak acid content
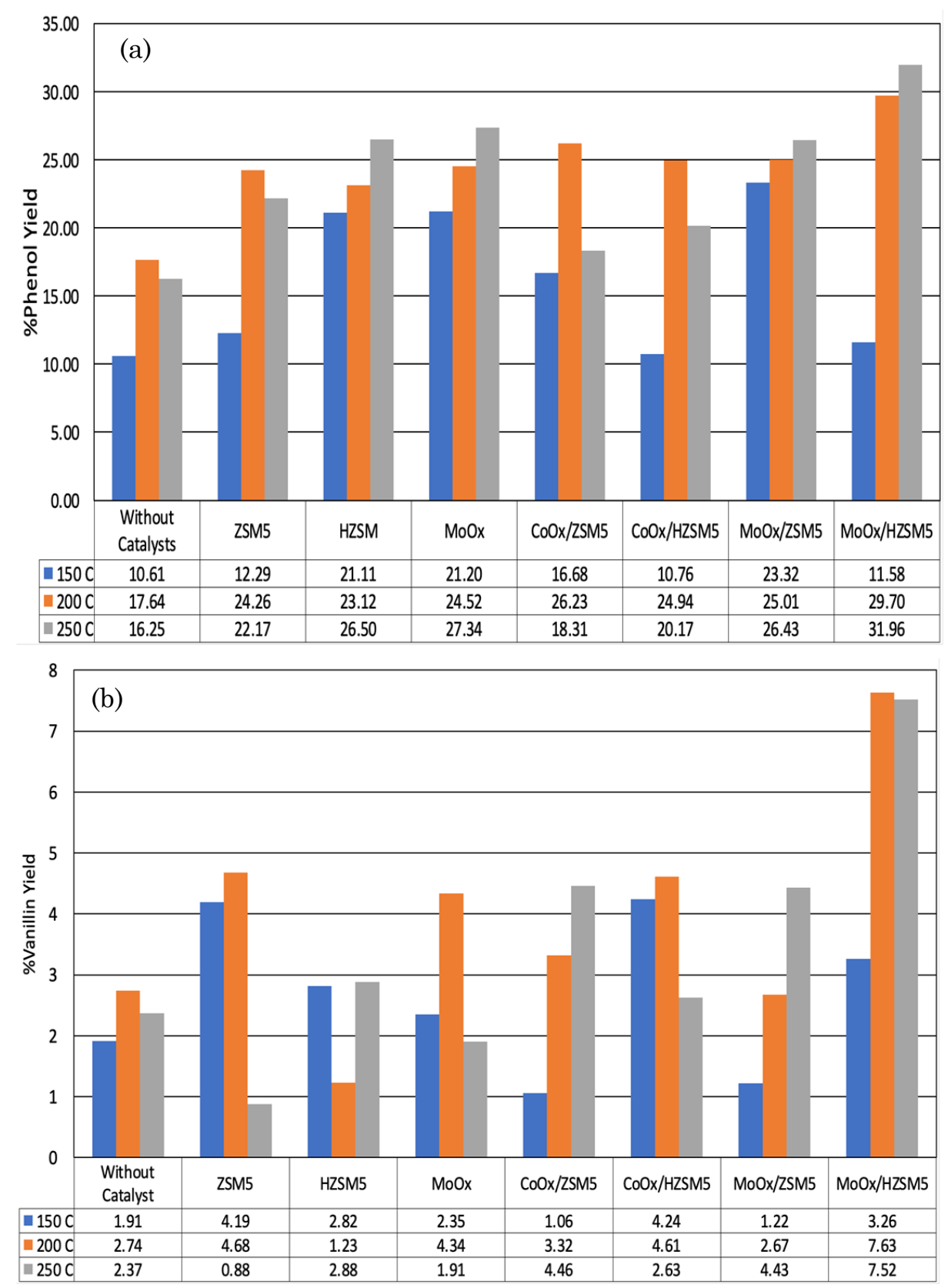

Figure 8. Percentage of yield of (a) phenol and (b) vanillin from DPE substrate over as-prepared Catalysts, reaction condition: $\mathrm{P} \mathrm{N}_{2}=2$ atm DPE : catalyst ratio $=0.25 \mathrm{~g}: 0.125 \mathrm{~g}$, solvent used (ethanol: $\mathrm{H}_{2} \mathrm{O}$ ) = 1:1 in total volume was $25 \mathrm{~mL}$ 
above $40 \%$ shows the highest production of phenol and vanillin at a reaction temperature of $200-250{ }^{\circ} \mathrm{C}$. It was also reported by Jiang et al. that cleavage of diphenyl ether $\mathrm{C}-\mathrm{O}$ bond optimally facilitated over weakly acidic catalyst in $220{ }^{\circ} \mathrm{C}[51]$.

Moreover, in more detail on the $\mathrm{NH}_{3}$-TPD analysis, apart from the number of catalyst acid sites, the ability of the modified Mo oxide catalyst in adsorbing and desorbing substrate molecules (base species) from the surface greatly supports the performance of heterogeneous catalysts, where the ability of the active site of the catalyst to adsorb-desorb substrates and products is one of the important factors. Furthermore, the Navajas et al. also reported that the Molybdenum oxides have interesting activity regarding the active sites as the Lewis acid and the Brönsted acid in the conversion of vegetable oil [52]. Considering the Lewis acidity, the molybdenum species could provide the orbital $d$ and can form the reactive transition state with the substrate and lead the lower energy pathway in the reaction. It showed that increasing acidity in the low-temperature region could support the conversion reaction in mild conditions due to the ability to give the hydrogen from the surface to react with the substrate. Furthermore, supported by Ben et al. the existence of hydrogen as the Brönsted acid site in catalyst can facilitate some reactions in lignin conversions, such as hydrodeoxygenation (the carbocation formed by dehydration), followed by cleavage ether bond, decarboxylation, or cleavage of the $\mathrm{C}-\mathrm{C}$ bond [53].

In addition to the acidity of the catalyst, it is also seen that the mesopore size influences the tendency for the formation of phenol and vanillin products in the catalyst. The presence of mesopore in the catalyst increases the catalytic effectiveness, where the larger the size of the mesopore, the higher the yield of the desired product [54,55]. In this study, the mesopore size above $9 \mathrm{~nm}$ gives the highest production of phenol and vanillin.

Interestingly, although it has a dominance of a weak acid, if the catalyst does not have a large mesopore size, then the production of phenol and vanillin is not optimal. It can be seen in catalytic activity, where $\mathrm{MoO}_{\mathrm{x}} / \mathrm{ZSM}-5$ with $48 \%$ weak acid but only $2.16 \mathrm{~nm}$ mesopore size resulted in the production of phenol and vanillin under the $\mathrm{MoO}_{x} / \mathrm{HZSM}-5$ catalyst, which had $42 \%$ weak acid content with $9.28 \mathrm{~nm}$ mesopore size. The size of the mesopore greatly affects the ability of the substrate and product to diffuse into the pore. Kantarelis et al. also reported that the coke formation formed during the reaction and led to the blockage in the pore [7]. Meanwhile, with the larger pore size (by introducing mesoporosity), this drawback can be overcome. Therefore, this work revealed that the yield of phenol and vanillin products in the catalytic reaction of DPE as a lignin model compound was correlated with the content of weak acid on the catalyst and, at the same time, the mesopore size in the catalyst. Therefore, this study can recommend that ZSM-5 synthesized with higher weak acid content and large mesoporosity can facilitate the conversion of lignin at the mild condition with low temperatures, ranging from $200-250{ }^{\circ} \mathrm{C}$.

\subsection{Proposed Reaction Mechanism}

Based on Figure 9 and considering the resulting yield, the DPE conversion mechanism is thought to be initiated by the formation of phenol followed by vanillin. This reaction is fa-

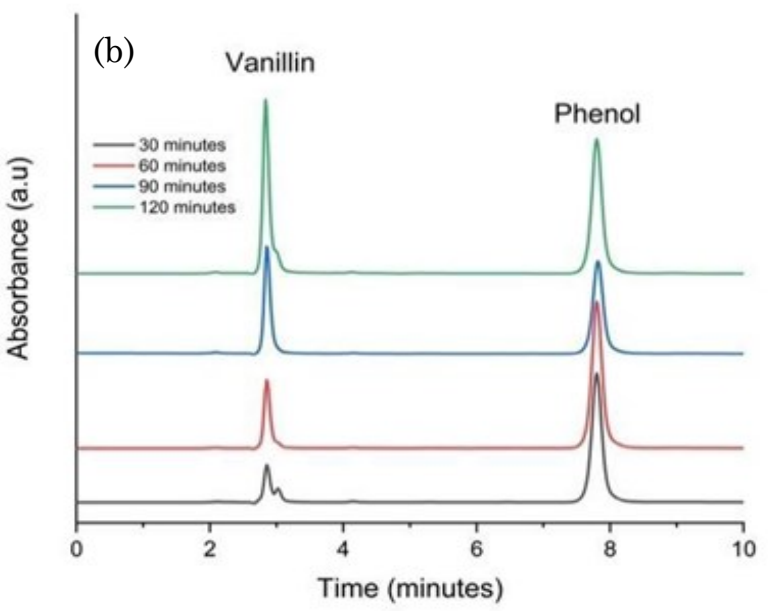

Figure 9. (a) Percentage of yield of phenol and vanillin, and (b) Chromatogram of product from DPE substrate over Mo/HZSM-5 catalyst in various time reaction 
cilitated by hydrogen on the catalyst surface and breaks the ether bond [44]. It is similar to the observation by Yao et al. that phenol is the major product of conversion DPE in $140{ }^{\circ} \mathrm{C}$ in one hour reaction by the hydrodeoxygenation pathway [39]. This reaction begins with the adsorption of the substrate molecule on its oxygen (base substituent) on the acidic side of catalyst, probably the Mo oxide on the surface of the catalyst and is followed by a chemical reaction on the surface due to the presence of hydrogen in the catalyst surface. It has been reported the Mo-based catalysts selectively break $\mathrm{C}-\mathrm{O}$ bond, meanwhile preserve the aromatic ring [53]. Moreover, Mo oxide species is generally considered as the originate of high hydrodeoxygenation activity over Mo-based catalysts [54]. The reaction continues to produce vanillin, the presence of supported Mo oxide facilitates the reaction of the oxidation from ethanol as a solvent to an aldehyde substituent, supported by report in $[11,55]$. The presence of Brönsted acid in the catalyst surface leads to the formation of a carbocation and termination of the $\mathrm{C}-\mathrm{C}$ bond to produce methoxy, similar to the report in [50]. The description of these stages can be seen in Figure 10.

\section{Conclusions}

In this study, the as-synthesized and modified ZSM-5 catalysts from alternative precursors i.e Indonesian zeolite and Kaolin showed physicochemical properties that have met the criteria for good heterogeneous catalyst in DPE lignin model compound conversion to phenol and vanillin. The relationship between the physicochemical properties of the catalysts has been investigated. To conclude, $\mathrm{MoO}_{\mathrm{x}} / \mathrm{HZSM}-5$ catalyst, which has dominance of weak acid composition above $40 \%$ and with the mesopore size of $9 \mathrm{~nm}$, showed the highest \% yields of phenol and vanillin, at reaction temperature of $200-250{ }^{\circ} \mathrm{C}$ in 30 minutes reaction.
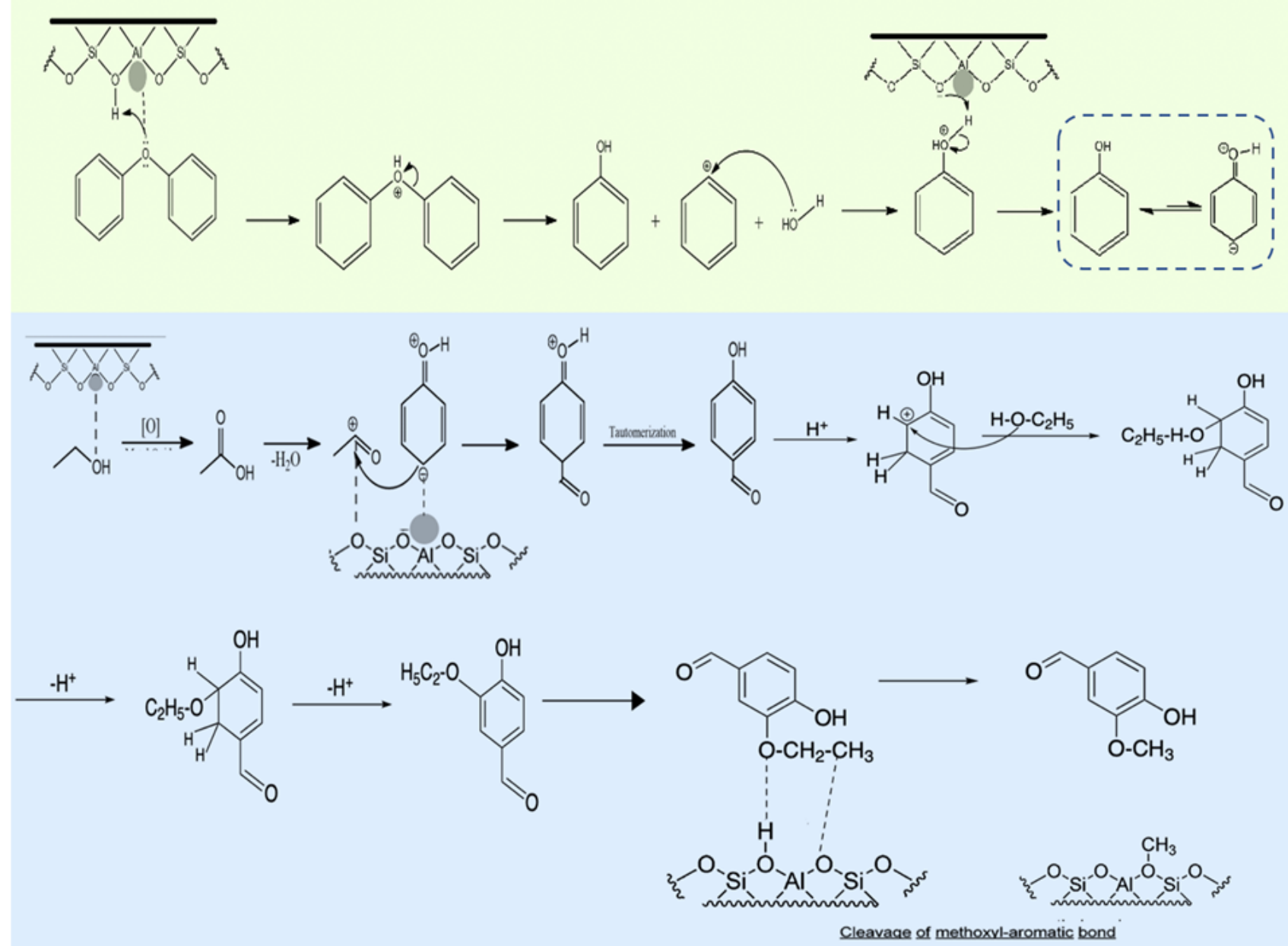

Figure 10. Proposed mechanism to produce vanillin from DPE with phenolic compound as the intermediate over $\mathrm{MoO}_{\mathrm{x}} / \mathrm{HZSM}-5$ catalyst 


\section{Acknowledgements}

Author would like to thanks to Kemenristek/BRIN which supporting financial support on this research with Hibah PTUPT (Penelitian Terapan Unggulan Perguruan Tinggi) with contract number: NKB269/UN2.RST/HKP.05.00/2021.

\section{References}

[1] Li, C., Zhao, X., Wang, A., Huber, G.W., Zhang, T. (2015). Catalytic Transformation of Lignin for the Production of Chemicals and Fuels. Chem. Rev., 115 (21), 11559-11624. DOI: 10.1021/acs.chemrev.5b00155.

[2] Guadix-Montero, S., Sankar, M. (2018). Review on Catalytic Cleavage of $\mathrm{C}-\mathrm{C}$ Inter-unit Linkages in Lignin Model Compounds: Towards Lignin Depolymerisation. Top. Catal., 61 (3-4), 183-198, DOI: 10.1007/s11244-0180909-2.

[3] Liu, C., Wu, S., Zhang, H., Xiao,R. (2019). Catalytic oxidation of lignin to valuable biomass-based platform chemicals: A review. Fuel Process. Technol., 191, 181-201, DOI: 10.1016/j.fuproc.2019.04.007

[4] Mauriello, F.F., Paone, E., Pietropaolo, R., Balu, A.M., Luque, R. (2018). Catalytic transfer hydrogenolysis of lignin derived aromatic ethers promoted by bimetallic $\mathrm{Pd} / \mathrm{Ni}$ systems. ACS Sustainable Chem. Eng. 6 (7), $\begin{array}{lllllllllllllll}9 & 2 & 6 & 9 & - & 9 & 2 & 7 & 6 & , & & \text { D } & \text { O } & \text { I : }\end{array}$ 10.1021/acssuschemeng.8b01593.

[5] Hu, C., Zhang, H., Wu, S., Xiao, R. (2020). Molecular shape selectivity of HZSM-5 in catalytic conversion of biomass pyrolysis vapors: The effective pore size. Energy Conversion and Management, 210, 112678. DOI: 10.1016/j.enconman.2020.112678.

[6] Deepa, A.K., Dhepe, P.L. (2014). Solid acid catalyzed depolymerization of lignin into value added aromatic monomers. RSC Adv., 4 (25), 12625-12629, DOI: 10.1039/c3ra47818a.

[7] Kantarelis, E., Javed, R., Stefanidis, S., Psarras, A., Iliopoulou, E., Lappas, A. (2019). Engineering the Catalytic Properties of HZSM5 by Cobalt Modification and Post-synthetic Hierarchical Porosity Development. Top Catal., 62 (7-11), 773-785, DOI: 10.1007/s11244-01901179-w.

[8] Xie, W., Liang, J., Morgan, H.M., Zhang, X., Wang, K., Mao, H., Bu, Q. (2018). Ex-situ catalytic microwave pyrolysis of lignin over Co/ZSM-5 to upgrade bio-oil. Journal of Analytical and Applied Pyrolysis, 132, 163-170. DOI: 10.1016/j.jaap.2018.03.003.
[9] Ma, Z., Custodis, V., Van Bokhoven, J.A. (2014). Selective deoxygenation of lignin during catalytic fast pyrolysis. Catal. Sci. Technol., 4 (3), 766-772. DOI: 10.1039/c3cy00704a.

[10] Sun, L., Wang, Z., Chen, L., Yang, S., Xie, X., Gao, M., Zhao, B., Si, H., Li, J., Hua, D. (2020). Catalytic Fast Pyrolysis of Biomass into Aromatic Hydrocarbons over MoModified ZSM-5 Catalysts. Catalysts, 10(9), 1051. DOI: 10.3390/catal10091051.

[11] Zhang, L., Wang, Y., Zhang, L., Chi, Z., Yang, Y., Zhang, Z., Zhang, B., Lin, J., Wan, S. (2020). Hydrogenolysis of Aryl Ether Bond over Heterogeneous Cobalt-Based Catalyst. Industrial \& Engineering Chemistry Research, 59 (39), 17357-17364. DOI: 10.1021/acs.iecr.0c01374

[12] Prasomsri, T., Nimmanwudipong, T., RománLeshkov, Y. (2013). Effective hydrodeoxygenation of biomass-derived oxygenates into unsaturated hydrocarbons by $\mathrm{MoO}_{3}$ using low $\mathrm{H}_{2}$ pressures. Energy \& Environmental Science, 6(6), $1732-1738$. DOI: 10.1039/c3ee24360e

[13] Jing, Y., Dong, L., Guo, Y., Liu, X., Wang, Y. (2019). Chemicals from lignin: a review of the catalytic conversion involving hydrogen. ChemSusChem, 13 (17), 4181-4198. DOI: 10.1002/cssc. 201903174

[14] Asghari, A., Khorrami, M.K., Kazemi, S.H. (2019). Hierarchical H-ZSM5 zeolites based on natural kaolinite as a high-performance catalyst for methanol to aromatic hydrocarbons conversion. Scientific Reports, 9(1), 17526. DOI: 10.1038/s41598-019-54089-y.

[15] Krisnandi, Y.K., Saragi, I.R., Sihombing, R., Ekananda, R., Sari, I.P., Griffith, B.E., Hanna, J.V. (2019). Synthesis and Characterization of Crystalline NaY-Zeolite from Belitung Kaolin as Catalyst for n-Hexadecane Cracking. Crystals, 9 (8), 404-417. DOI: 10.3390/cryst9080404.

[16] Yue, Y., Kang, Y., Bai, Y., Gu, L., Liu, H., Bao, J., Wang, T., Yuan, P., Zhu, H., Bai, Z., Bao, X. (2018). Seed-assisted, template-free synthesis of ZSM-5 zeolite from natural aluminosilicate minerals. Applied Clay Science, $158, \quad 177-185 . \quad$ D O I : 10.1016/j.clay.2018.03.025

[17] Pratama, A.P., Krisnandi, Y.K., Abdullah, I. (2020). Catalytic depolymerization of lignin from wood waste biomass over natural sourced ZSM-5 catalysts Catalytic depolymerization of lignin from wood waste biomass over natural sourced ZSM-5 catalysts. In IOP Conference Series: Materials Science and Engineering pp. 1-8. 4th International Symposium on Current Progress in Functional Materials 2019. DOI: $10.1088 / 1757$. 899X/902/1/012051 
[18] Rohayati, R., Krisnandi, Y.K., Sihombing, R. (2017). Synthesis of ZSM - 5 zeolite using Bayat natural zeolite as silica and alumina source Synthesis of ZSM - 5 Zeolite Using Bayat Natural Zeolite as Silica and Alumina Source. In AIP Conference Proceedings. International symposium on current progress in mathematics and sciences (ISCPMS 2016) 1862, 030094. DOI: 10.1063/1.4991198.

[19] Wang, L., Zhang, Z., Yin, C., Shan, Z., Xiao, F. (2010) Microporous and Mesoporous Materials Hierarchical mesoporous zeolites with controllable mesoporosity templated from cationic polymers, Microporous and Mesoporous Materials, 131 (1-3), 58-67, DOI: 10.1016/j.micromeso.2009.12.001.

[20] Wang, X., Du, B., Pu, L., Guo, Y., Li, H., Zhou, J. (2018). Effect of particle size of HZSM-5 zeolite on the catalytic depolymerization of organosolv lignin to phenols, J. Anal. Appl. Pyrolysis, 129, 13-20, DOI: 10.1016/j.jaap.2017.12.011.

[21] Che, Q., Yang, M., Wang, X., Yang, Q., Rose Williams, L., Yang, H., Zou, J., Zeng, K., Zhu, Y., Chen, Y., Chen, H. (2019). Influence of physicochemical properties of metal modified ZSM-5 catalyst on benzene, toluene and $\mathrm{xy}$ lene production from biomass catalytic pyrolysis. Bioresource Technology, 278, 248-254. DOI: 10.1016/j.biortech.2019.01.081.

[22] Krisnandi, Y.K., Putra, B.A.P., Bahtiar, M., Zahara, Z., Abdullah, I., Howe, R.F. (2015). Partial Oxidation of Methane to Methanol over Heterogeneous Catalyst Co/ZSM-5. Procedia Chemistry, 14, 508-515. DOI: 10.1016/j.proche.2015.03.068.

[23] Liu, B., France, L., Wu, C., Jiang, Z., Kuznetsov, V.L., Al-Megren, H.A., Al-Kinany, M., Aldrees, S.A., Xiao, T., Edwards, P.P. (2015). Methanol-to-hydrocarbons conversion over $\mathrm{MoO}_{3} / \mathrm{H}-\mathrm{ZSM}-5$ catalysts prepared via lower temperature calcination: a route to tailor the distribution and evolution of promoter Mo species, and their corresponding catalytic properties, Chem. Sci., 6 (9), 5152-5163, DOI: $10.1039 / \mathrm{c} 5 \mathrm{sc} 01825 \mathrm{k}$.

[24] Caldeira, V.P.S., Santos, A.G.D., Pergher, S.B.C., Costa, M.J.F., Araujo, A.S. (2016), Use of a low-cost template-free zsm-5 for atmospheric petroleum residue pyrolysis, Quim. Nova, 39 (3), 292-297, DOI: 10.5935/01004042.20160019.

[25] Colella, C., Wise, W.S. (2014). The IZA Handbook of Natural Zeolites: A tool of knowledge on the most important family of porous minerals. Microporous Mesoporous Mater., 189, 4-10, DOI: 10.1016/j.micromeso.2013.08.028.
[26] Omar, B.M., Bita, M., Louafi, I., Djouadi, A. (2018), Esterification process catalyzed by ZSM-5 zeolite synthesized via modified hydrothermal method, Methods X, 5, 277-282, DOI: 10.1016/j.mex.2018.03.004.

[27] Sun, J., Wang, H., Li, Y., Zhao, M. (2021). Porous $\mathrm{Co}_{3} \mathrm{O}_{4}$ column as a high-performance Lithium anode material. J. Porous Mater., 28 (3), 889-894, DOI: 10.1007/s10934-02101041-z.

[28] Li, Z., Yang, J., Zhou, Y., Cui, J., Ma, Y., Geng, C., Kang, Y., Liu, J., Yang, C. (2020). Influence of different preparation methods on the activity of Ce and Mo co-doped ZSM-5 catalysts for the selective catalytic reduction of NOx by $\mathrm{NH}_{3}$, Environ. Sci. Pollut. Res., 27 (32), 40495-40503, DOI: 10.1007/s11356-02010052-3.

[29] Zhang, Y., Zhu, K., Duan, X., Li, P., Zhou, X., Yuan, W. (2014). Synthesis of hierarchical ZSM-5 zeolite using CTAB interacting with carboxyl-ended organosilane as a mesotemplate. $R S C A d v$., 4 (28), 14471-14474, DOI: 10.1039/c3ra46646a.

[30] Wang, L., Xu, Y., Tan, X., Tapas, S., Zhang, J. (2017). Aim and shoot: Molecule-imprinting polymer coated $\mathrm{MoO}_{3}$ for selective SERS detection and photocatalytic destruction of lowlevel organic contaminants. RSC Adv., vol. 7, no. 58, pp. 36201-36207, DOI: 10.1039/c7ra05547a.

[31] Anuradha, C.T., Raji, P. (2020). Facile synthesis and characterization of $\mathrm{Co}_{3} \mathrm{O}_{4}$ nanoparticles for high-performance supercapacitors using Camellia sinensis. Appl. Phys. A Mater. Sci. Process., 126 (3), DOI: 10.1007/s00339020-3352-8.

[32] Zhou, X.J., Shi, P.H., Qin, Y.F., Fan, J.C., Min, Y.L., Yao, W.F. (2016). Synthesis of $\mathrm{Co}_{3} \mathrm{O}_{4} /$ graphene composite catalysts through CTAB-assisted method for orange II degradation by activation of peroxymonosulfate. $J$. Mater. Sci. Mater. Electron., 27 (1), 10201030, DOI: $10.1007 / \mathrm{s} 10854-015-3847-9$.

[33] Krisnandi, Y.K., Nurani, D.A., Reza, M., Samodro, B.A., Suwardiyanto, S., Susianto, N., Putrananda, A.T., Saragi, I.R., Umar, A., Choi, S.-M., Howe, R.F. (2019). Partial Oxidation of Methane to Methanol on Cobalt OxideModified Hierarchical ZSM-5. Biogas - Recent Advances and Integrated Approaches May, Intech Open Publisher. DOI: 10.5772/intechopen.86133.

[34] Cui, H.J., Shi, J.W., Yuan, B., Fu, M.L. (2013). Synthesis of porous magnetic ferrite nanowires containing $\mathrm{Mn}$ and their application in water treatment. J. Mater. Chem. A, 1 (19), 5902-5907, DOI: 10.1039/c3ta01692g. 
[35] Goyal, A., Bansal, S., Samuel, P., Kumar, V., Singhal, S. (2014). $\mathrm{CoMn}_{0.2} \mathrm{Fe}_{1.8} \mathrm{O}_{4}$ ferrite nanoparticles engineered by sol-gel technology: An expert and versatile catalyst for the reduction of nitroaromatic compounds. J. Mater. Chem. A, 2 (44), 18848-18860, DOI: 10.1039/c4ta03900a.

[36] Krisnandi, Y.K., Nurani, D.A., Alfian, D.V., Sofyani, U., Faisal, M., Saragi, I. R., Pamungkas, A.Z., Pratama, A.P. (2021). The new challenge of partial oxidation of methane over $\mathrm{Fe}_{2} \mathrm{O}_{3} / \mathrm{NaY}$ and $\mathrm{Fe}_{3} \mathrm{O}_{4} / \mathrm{NaY}$ heterogeneous catalysts. Heliyon, 7 (11), 0-7, DOI: 10.1016/j.heliyon.2021.e08305.

[37] Kosinov, N., Coumans, F.J.A.G., Li, G., Uslamin, E., Mezari, B., Wijpkema, A.S.G., Pidko, E.A., Hensen, E.J.M. (2017). Stable Mo/HZSM-5 methane dehydroaromatization catalysts optimized for high-temperature calcination-regeneration. J. Catal., 346, 125133, DOI: 10.1016/j.jcat.2016.12.006.

[38] Abdelsayed, V., Smith, M.W., Shekhawat, D. (2015). Investigation of the stability of $\mathrm{Zn}$ based HZSM-5 catalysts for methane dehydroaromatization. Appl. Catal. A Gen., 505, 365-374, DOI: 10.1016/j.apcata.2015.08.017.

[39] Lónyi, F., Valyon, J. (2001), On the interpretation of the $\mathrm{NH}_{3}$-TPD patterns of H-ZSM-5 and H-mordenite, Microporous Mesoporous Mater., 47 (2-3), 293-301. DOI: 10.1016/s1387-1811(01)00389-4

[40] Wei, Z., Chen, l., Cao, Q., Wen, Z., Zhou, Z., Xu, Y., Zhu, X. (2017). Steamed Zn/ZSM-5 catalysts for improved methanol aromatization with high stability, Fuel Process. Technol.,

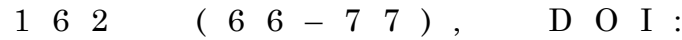
10.1016/j.fuproc.2017.03.026.

[41] Liu, C., Wang, H., Karim, A.M., Sun, J., Wang, Y. (2014). Catalytic fast pyrolysis of lignocellulosic biomass. Chem. Soc. Rev., 43 (22), 7594-7623, DOI: 10.1039/c3cs60414d.

[42] Yao, G., Wu, G., Dai, W., Guan, N., Li, L. (2015), Hydrodeoxygenation of lignin-derived phenolic compounds over bi-functional $\mathrm{Ru} / \mathrm{H}$ Beta under mild conditions, Fuel, 150, 175183. DOI: 10.1016/j.fuel.2015.02.035.

[43] Zhao, C., Lercher, J.A. (2012), Selective Hydrodeoxygenation of Lignin-Derived Phenolic Monomers and Dimers to Cycloalkanes on $\mathrm{Pd} / \mathrm{C}$ and HZSM-5 Catalysts, ChemCatChem, 4 (1), 64-68, DOI: 10.1002/cctc.201100273.

[44] Guo, M., Peng, J., Yang, Q., Li, C. (2018). Highly Active and Selective RuPd Bimetallic NPs for the Cleavage of the Diphenyl Ether C-O Bond. ACS Catal., 8 (12), 11174-11183, DOI: 10.1021/acscatal.8b03253.
[45] Jiang, L., Guo, H., Li, C., Zhou, P., Zhang, Z. (2019), Selective cleavage of lignin and lignin model compounds without external hydrogen, catalyzed by heterogeneous nickel catalysts, Chem. Sci., 10 (16), 4458-4468, DOI: 10.1039/c9sc00691e.

[46] Zheng, A., Zhao, Z., Chang, S., Huang, Z., Wu, H., Wang, X., He, F., Li, H. (2014). Effect of crystal size of ZSM-5 on the aromatic yield and selectivity from catalytic fast pyrolysis of biomass. Journal of Molecular Catalysis A: Chemical, 383-384, 23-30. DOI: 10.1016/j.molcata.2013.11.005.

[47] Denardin, F.G., Perez-Lopez, O.W. (2019). Methane dehydroaromatization over $\mathrm{Fe}$ M/ZSM-5 catalysts $(\mathrm{M}=\mathrm{Zr}, \mathrm{Nb}, \mathrm{Mo}), \mathrm{Mi}$ croporous and Mesoporous Materials, 295, 109961. DOI: 10.1016/j.micromeso.109961.

[48] Engtrakul, C., Mukarakate, C., Starace, A.K., Magrini, K.A., Rogers, A.K., Yung, M.M. (2015). Effect of ZSM-5 acidity on aromatic product selectivity during upgrading of pine pyrolysis vapors. Catalysis Today, 269, 175181. DOI: 10.1016/j.cattod.2015.10.032.

[49] Amakawa, K., Wang, Y., Kröhnert, J., Schlögl, R., Trunschke, A. (2019), Acid sites on silica-supported molybdenum oxides probed by ammonia adsorption: Experiment and theory, Molec. Catal., 478, 110580, DOI: 10.1016/j.mcat.2019.110580.

[50] Maddi, B., Davidson, S., Job, H., Dagle, R., Guo, M., Gray, M., Ramasamy, K.K. (2020). Production of Gaseous Olefins from Syngas over a Cobalt-HZSM-5 Catalyst. Catalysis Letters, $151 \quad$ (2), 526-537. DOI: 10.1007/s10562-020-03324-7.

[51] Jiang, W., Cao, J.-P., Zhu, C., Xie, T., Zhao, X.-Y., Zhao, M., Bai, H.C. (2021). Selective cleavage of lignin-derived diphenyl ether C-O bond over weakly acidic $\mathrm{Ni} / \mathrm{Nb}_{2} \mathrm{O}_{5}$ catalyst. Fuel, $\quad 295, \quad 120635$. D O I : 10.1016/j.fuel.2021.120635

[52] Navajas, A., Jim, E., Romero-sarria, F. (2020). Molybdenum Oxide for the Production of Biodiesel from Oil with High Free Fatty Acids Content. Catalysts, 10(2), 158. DOI: 10.3390/catal10020158.

[53] Ben, H., Ragauskas, A. J. (2013). Influence of Si/Al Ratio of ZSM-5 Zeolite on the Properties of Lignin Pyrolysis Products. ACS Sustainable Chemistry \& Engineering, 1(3), 316-324. DOI: $10.1021 / \mathrm{sc} 300074 \mathrm{n}$

[54] Smail, H.A., Rehan, M., Shareef, K.M., Ramli, Z., Nizami, A.S., Gardy, J. (2019). Synthesis of uniform mesoporous zeolite ZSM-5 catalyst for friedel-crafts acylation. ChemEngineering, 3 (2), $1-11, \quad$ D O I : 10.3390/chemengineering3020035. 
[55] Gläser, R., Juan Carlos, U.R., Lazaridis, P.A., Fotopoulos, A.P., Karakoulia, S.A., Triantafyllidis, K.S. (2018). Catalytic Fast Pyrolysis of Kraft Lignin With Conventional, Mesoporous and Nanosized ZSM-5 Zeolite for the Production of Alkyl-Phenols and Aromatics. Front. C hem. $\quad 1, \quad 295, \quad$ D O I : 10.3389/fchem.2018.00295.
[56] Zhang, W., Oyama, S.T. (1996), In situ laser Raman studies of intermediates in the catalytic oxidation of ethanol over supported molybdenum oxide, J. Phys. Chem., 100 (25), 10759-10767, DOI: 10.1021/jp960917d 